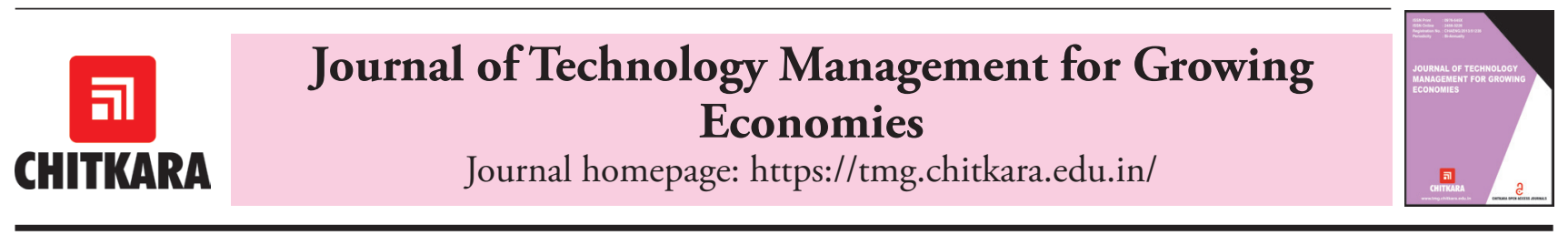

\title{
Real World of Artificial Intelligence - A Review
}

\author{
Madhu Dhiman', Mansi Tonk ${ }^{2}$, Ramneet Kaur ${ }^{3}$ and Amandeep Kaur ${ }^{4}$ \\ ${ }^{1,2,3,4}$ Chitkara Institute of Engineering and Technology, Chitkara University, Punjab-140401, India \\ 1'mdhman1522.ca19@chitkara.edu.in \\ ${ }^{2}$ mtonk1523.ca19@chitkara.edu.in \\ 3rkaur1540.ca19@chitkara.edu.in \\ ${ }^{4}$ amandeep.bhullar@chitkara.edu.in (Corresponding Author)
}

\section{ARTICLE INFORMATION}

Received: June 18, 2020

Revised: August 05, 2020

Accepted: August 24, 2020

Published Online: November 16, 2020

Keywords:

Artificial Intelligence, Knowledge Based

Systems, Robotics

DOI: $10.15415 /$ jtmge.2020.112005

\section{ABSTRACT}

Artificial Intelligence is the combination of machine and human intelligence, which are in research trends from the last many years. Different Artificial Intelligence programs have become capable of challenging humans by providing Expert Systems, Neural Networks, Robotics, Natural Language Processing, Face Recognition and Speech Recognition. Artificial Intelligence brings a bright future for different technical inventions in various fields. This review paper shows the general concept of Artificial Intelligence and presents an impact of Artificial Intelligence in the present and future world.

\section{Introduction}

Artificial Intelligence is a machine intelligence to simulate human thinking with machines which plays a vital role in developing the social economical society in recent years. It results in more development of human beings thereby transforming them in terms of mobile phones, face recognition and intelligent voice etc. The term Artificial Intelligence can be splitted into two individual aspects i.e. both artificiality and intelligence. As an artificial aspect, the simulation of certain things used as a learning environment can be taken into consideration. As an intelligence aspect, it has more complexity in terms of smart based computer analysis and calculations resulting from human thinking. So, it is referred to as a process of simulating human thinking and consciousness for researching and developing technologies and theories etc. In the present scenario, the area of artificial intelligence is getting more mature and perfect. Due to increase in demand by people, many applications have broader prospects in Network Management, Agent Technology Application and in System Evaluation. Though it still possesses certain problems in analysis of data. Artificial Intelligence is a machine intelligence to think and learn which makes computer smart and capable of performing different tasks simultaneously within a few seconds. This came into existence in 1956 and has become an important part in every field such as Engineering, Business Development, Science and Technology, Medical Research and Education System. It enables to transform the visual perception of anything into virtual reality. It identifies the genomic footprint of a previously unknown human ancestor (Breazeal, Gray \& Berlin, 2009). Expert systems automatically interpret data from the external world and interpret results to further use for flexible adaptation in current systems. A gadget of artificial intelligence has powered brain implant that can turn human thoughts into speech. It is classified as Analytical, Human-inspired and Humanized Artificial Intelligence. Analytically it is one of the most popular cognitive intelligence, which means the ability to handle reasoning, solving problems, applying tricks, thinking abstractly, comprehend complex ideas, learning quickly from experience. Another classification of Analytical Intelligence is reactive machines in which information about past events never stored. Human-inspired Intelligence is one of the difficult tasks to perform as these machines do their work without manual support. It is a combination of cognitive and social intelligence. Human-inspired artificial intelligence (AI) is further classified as weak or narrow and 
strong AI's. Machines under weak or narrow AI are not too smart and intelligent. Strong AI machines can think and perform tasks on their own, just like human beings. Till now there are no such applications of Human-inspired AI, but researchers are trying to make a machine which can think like human-being.

Humanized AI is further classified as theory of mind and self-awareness. Theory of Mind AI is intelligence in which machines have the same emotions as human-being, such as beliefs, thoughts, and expectations. Self-awareness AI has its own conscious and super-intelligence features. AI indulges in many activities like reasoning, automated learning, robotics, scheduling and language processing. The reasoning is the first essential part of developing any Self-awareness AI machine. In this approach, the developer decides the system software which would generate conclusion from existing knowledge using logical techniques such as deduction and induction. Automatic learning and Scheduling is the next step for building Artificial Intelligence. Intelligent machines should be automatic so that humans can use the machines conveniently while the machines get automatically trained to do same task better in the future. Researchers at Uber AI Labs have designed an algorithm called POET (Paired Open-Ended Trailblazer) which creates a new environment and solves them at the same time. Natural Language Processing is a method by which the machine learns human languages and also does automatic manipulation of natural languages like speech and text using software. Machine vision captures visual information using a camera and analysis it working as a human eye. Robotics is used to perform the task efficiently and consistently according to the design and manufacturing parameters, which is difficult for human-beings. General Intelligence is the intelligence of a machine which can perform any intellectual task of human being successfully. Big companies such as Google, Facebook, Microsoft and others are investing heavily on intelligent and smart machines. However, it is to yet to be proven that all $\mathrm{AI}$ is here for the good of mankind. Mathematical theory is integrated with algorithms and run on a specific platform in order to make decisions. All these parameters suggest building applications for the achievement of good results. Software development companies are offering innovative solutions for their business. A Systematic review of different researchers on Machine Intelligence is presented in the next section.

\section{Literature Review}

Many researchers are working on artificial intelligence in different fields, using an amalgamation of different technologies. Robert Kowalski, 2011 brought a model of ALP (Abdicative Logic Programming) agents. This model embeds ALP in agent cycle and is of both descriptions. ALP is also called as the descriptive model, as it includes classical logic and is compatible with classical decision theory. ALP helps us to improve human thinking and to communicate more effectively with other people and make better decisions in our lives. The ALP agents' goals are generally casual, with the expressive, powerful first-order logic (FOL). The author defined the basic ALP agent cycle, which included observation, goal maintenance, forward reasoning, backward reasoning, cones-forward reasoning, goal achievements, decision making, action and stimulus-response associations. The researcher also believed in this application for the future without defining the collaboration in artificial intelligence in more humanistic disciplines. Brunette et al. (2009) shared two concepts-Baar's Global Workspace Theory and the Agent-Based Model. The author also defined top-down and bottom-up approaches. The top-down approach starts with higher-level functions and implements those operations. The bottom-up approach is at the neuron level and earmarked to create higher-level functions as well. The authors discussed the "Logical Theorist" (Oke, 2008) stated robotics AI in three dimensions i.e. navigation, robot's localization and robot's participation in agent term. Robots become the helping hand for humans with a secured environment, as a device equipped with Artificial Intelligence can reduce pollution conservation and recycling. As humans can understand the problems of fellow humans, similarly AI devices can easily understand the problem of the machine deployed for reducing human workload. Javier Anderu Perez et al. (2017) proposed a method of living Intelligence. Animals are also intelligent but are inferior to humans who are more creative and having an emotional sense for others and are self-aware for progressing. However, the major drawbacks of artificial intelligence are emotional intelligence and lack of common sense. A recent application was developed by Microsoft in the form of a Robot Toy to judge the compensation on the social network. However, it failed before its launch itself because of not being able to distinguish between a positive and negative interaction. Artificial Intelligence can only be limited to pain, fear, stress, and joy and sadness. To sustain the program of artificial intelligence, a rational and harmonic interaction is required between applicationspecific project and research idea. Robotics and Artificial Intelligence played a vital role in the United Kingdom. If in future, robots entirely overcome all limitations, then they could certainly help us to improve the economic growth. The author defined robots but did not mention the algorithm or formula for making the perfect robot.

Mohind et al. (2017) discussed various methods of machine learning which are supervised and unsupervised to reinforce machine learning. Supervised machine learning provides a correct solution for some specific inputs in 
neural networks. Unsupervised machine learning works on undetected patterns in a sample of data with minimum human interference. Reinforcement learning is computer interacts with a dynamic environment in which it must perform a specific task against the opponents. Jahanazib et al. (2015) evaluated Artificial Intelligence, whichever field it is being used, has facilitated life and provides a high potential for betterment and enhancing productivity. The origin of Artificial Intelligence back to the advancement made by Alex Turing during World War II in the decoding of messages. Thereafter, the research began to grow with the refined use of algebraic equations and analysis of text in different languages. However, the missing element in Artificial Intelligence is building human-level emotions in physical objects. Additionally, there are some open and upcoming challenges. E.g. in future, vehicle drivers could lose their jobs to AI-enabled robotics cars.

Shruti Anand et al. (2014) showed various legal and illegal impacts of Artificial Intelligence, including liability which is a middle level agreement in which law and order struggles to keep pace with the rapid changes. In this Andrew Matthias points out the liability with machines which are usually contingent upon its control. There are some proposed solutions for the regulation of Artificial Intelligence, similar to that in the early days of Internet. Jeremy strobe points out that the lack of regulation in later case allowed the Internet to develop its full potential. The regulation of the Artificial Intelligence in all stages and applications would be very challenging since Artificial Intelligence is already being used and developed by both entities- government and private such as product, negligence, service, malice and criminal liabilities. There are also some other frameworks which control the solution and many open challenges faced by the Artificial Intelligence in future. Severian et al. (2017) proposed an interactive cognitive architecture with some challenges. In the human-robot interaction context, the primary motive calls for integration and manipulation in basic knowledge with machine learning. Deliberated architecture and knowledge model follow some rules and regulations with HATP (human aware symbolic task planning), DIALOGS (natural language processing), assessments, action instantiation and MHP (human aware manipulation planning). According to Margaret A. Borden (1998), Artificial Intelligence is a skillful combination of imaginary creativity and transformational creativity. By analogy, imaginary creativity is creating new ideas from imagination and poetry. Continuing further, the authors discussed about exploratory and transformational creativity which involves the generation of ideas by exploring fundamental and new ideas, in a same way similar to scientists exploring new ideas by reading old books. Third computer models of creativity follow both types of creativity, which provide great support in building remote Artificial Intelligence. Different factors are supporting new ideas and facing new challenges. TJM et al. (2007) focused on the foundations of argumentation in Artificial Intelligence. Alvarado and Dyers approached the analysis of the presentation, which was used in the applications of relations. Diagrammatic treatment of argument structures involved in this approach for adoption of Artificial Intelligence in everything. There is a distinction between argument and argumentation, which can be related to union and interaction mathematical problems. There are some trending things in Artificial Intelligence like robotics, robotics bikes, driving cars, which would be very helpful for humans. Geortjel (2007) mentioned about integrated intelligent capabilities and a special track of AAAI (Association for the Advancement of Artificial Intelligence) in their paper. According to researchers, machine intelligence would improve the abilities in feedback cycles which are not possible only through human intelligence.

Jirgun et al. (2011) focused on probabilistic work for learning such as pose observations, model fitting, candidates' link models, structure selection and plotting of a graph for analysis. There are various observation models through which problems can be observed and solved. Candidates' link model is mostly used to service the robots having two bar links in it. A rigid model is one in which, there is a fixed relative transformation of two objects parts like parameters and arguments. The prismatic model consists of single-axis and co-dimensional data; the resolute model consists of onedimensional motion with circular arc and model evaluation. There is an approach in which there is a connection among various parts which constitutes articulated objects. However, researchers did not mention any approach or formula to implement their model. Akshata et al. (2017) mentioned about John McCarthy, who described the combination of the human ability to think, develop and apply Artificial Intelligence in the field of engineering. Civil engineering is a critical field to apply Artificial Intelligence and one of the parts of it is Artificial Neural Networks (ANN). ANN is used in designing, planning, construction and management of various infrastructures required for preparing offertenders of civil structures. There are different roles of various smart devices in civil engineering like structural health monitoring, self-repair model, structural engineering, waste management and concrete-mix designs. Structural Health Monitoring is used with monitoring sensors, for providing preventive maintenance and thereby increasing the life span of the structure. Self-Repair Models have some tubes containing resins; the tubes break to release the resin for repairing when sensing damage. The researcher provided the aspects of civil engineering but without showing the future aspect of his research (Patil et al., 2017). Shoshana (1986) proposed methods to dynamically represent spatial 
description. They proposed a model based expert system for neurological consultation by transforming psychological theories to machine reading with the help of various knowledge representation schemes. Nishika Gupta (2017) proposed an intelligent system to overcome the problem of communication between humans and machines. Verbal communication between humans is easy as it is enabled with voice and body gestures. Conversion of all human senses in a machine language is difficult and very complicated. Ronan (1995) discussed the implications of Artificial Intelligence and cognitive science. The most attractive framework is connectionism which facilitates the interaction of humans. Most probably an architect deals with yielding interesting computation underlined processes. These implications of Artificial intelligence suggest from the evolutionary point of view, which shows that language acts as an interface between human beings and computers. Researchers also showed the computational infrastructure upon which provides an interface between sensory and motor cortex but they did not define anything about physical metaphors in their work Table 1 shows the progress of Artificial Intelligence from the period of last ten years.

Table 1: Literature Review of previous 10 years from year 2010-2020.

\begin{tabular}{|c|c|c|c|c|}
\hline Year & Author(s) & Title of the Paper & $\begin{array}{l}\text { Journals/ } \\
\text { Conferences }\end{array}$ & Summary \\
\hline $\begin{array}{l}\text { 2020(Joolen, } \\
\text { 2020) }\end{array}$ & $\begin{array}{l}\text { Vincent van } \\
\text { Joolen }\end{array}$ & $\begin{array}{l}\text { Artificial Intelligence } \\
\text { and Robotics on the } \\
\text { Battlefields of } 2020\end{array}$ & $\begin{array}{l}\text { Strategy Research } \\
\text { Project, USAWC } \\
\text { class of } 2020\end{array}$ & $\begin{array}{l}\text { Military forces collaborate Artificial Intelligence into their } \\
\text { research projects. } \\
\text { And discussed role of military in Artificial Intelligence for } \\
\text { next twenty years. } \\
\text { As well as shows future battlefield environment. }\end{array}$ \\
\hline $\begin{array}{l}2019 \text { (Linde, } \\
\text { 2019) }\end{array}$ & $\begin{array}{l}\text { Helmut } \\
\text { Linde }\end{array}$ & $\begin{array}{l}\text { A white paper on the } \\
\text { future of artificial } \\
\text { intelligence }\end{array}$ & WhitePaper, 2019 & $\begin{array}{l}\text { Discussed the performance of Neural Network in } \\
\text { progressive improvement in techniques of Artificial } \\
\text { Intelligence and focused on interdisciplinary research }\end{array}$ \\
\hline $\begin{array}{l}2018 \text { (De } \\
\text { Felice, et al., } \\
\text { 2018) }\end{array}$ & $\begin{array}{l}\text { De Felice, } \\
\text { F; Petrillo, } \\
\text { A.; } \\
\text { Zomparelli }\end{array}$ & $\begin{array}{l}\text { Prospective design of } \\
\text { smart manufacturing: } \\
\text { An Italian pilot case } \\
\text { study }\end{array}$ & Manuf. Lett. 2018 & $\begin{array}{l}\text { Surveyed about foundations of argumentation in } \\
\text { Artificial Intelligence and analysis the influence of non- } \\
\text { classical logics. }\end{array}$ \\
\hline $\begin{array}{l}2017 \\
\text { (Indrasen, } \\
2017)\end{array}$ & $\begin{array}{l}\text { Poola } \\
\text { Indrasen }\end{array}$ & $\begin{array}{l}\text { How artificial } \\
\text { intelligence in } \\
\text { impacting real life }\end{array}$ & $\begin{array}{l}\text { International } \\
\text { Journal of Advance } \\
\text { Research and } \\
\text { Development, }\end{array}$ & $\begin{array}{l}\text { Highlighted the role of Artificial Intelligence in } \\
\text { automated transportation system and production } \\
\text { industries }\end{array}$ \\
\hline $\begin{array}{l}2016 \text { (Pérez- } \\
\text { Ortiz, et al., } \\
2016)\end{array}$ & Pérez-Ortiz & $\begin{array}{l}\text { A Review of } \\
\text { Classification Problems } \\
\text { and Algorithms in } \\
\text { Renewable Energy } \\
\text { Applications }\end{array}$ & Energies 2016 & $\begin{array}{l}\text { Reviewed classification algorithms as a tool for predictive } \\
\text { analysis in data interpretation. }\end{array}$ \\
\hline $\begin{array}{l}2015 \\
\text { (Shabbir } \\
\text { \& Anwer, } \\
2015)\end{array}$ & $\begin{array}{l}\text { Jahanzaib } \\
\text { Shabbir, } \\
\text { and Tarique } \\
\text { Anwer }\end{array}$ & $\begin{array}{l}\text { Artificial Intelligence } \\
\text { and its Role in Near } \\
\text { Future }\end{array}$ & $\begin{array}{l}\text { Journal of latex class } \\
\text { files, vol. } 14, \text { no. } 8 \\
\text { August } 2015\end{array}$ & $\begin{array}{l}\text { Highlighted modern AI basics in different fields and } \\
\text { explored how Human Intelligence differs from Machine } \\
\text { Intelligence }\end{array}$ \\
\hline $\begin{array}{l}2014 \text { (Renzi, } \\
\text { et al., 2014) }\end{array}$ & $\begin{array}{l}\text { C. Renzi, } \\
\text { F. Leali, M. } \\
\text { Cavazzuti, } \\
\text { and A. } \\
\text { Andrisano }\end{array}$ & $\begin{array}{l}\text { A review on } \\
\text { artificial intelligence } \\
\text { applications to the } \\
\text { optimal design } \\
\text { of dedicated and } \\
\text { reconfigurable } \\
\text { manufacturing systems }\end{array}$ & $\begin{array}{l}\text { The International } \\
\text { Journal of Advanced } \\
\text { Manufacturing } \\
\text { Technology }\end{array}$ & $\begin{array}{l}\text { Shown the immense scope in future for more productivity } \\
\text { and betterment with the origin of artificial intelligence }\end{array}$ \\
\hline $\begin{array}{l}2013 \text { (Tang, } \\
2013)\end{array}$ & Y. Tang & $\begin{array}{l}\text { Deep learning using } \\
\text { linear support vector } \\
\text { machines }\end{array}$ & arXiv preprint & $\begin{array}{l}\text { Highlighted various challenges in security, verification, } \\
\text { validity, and control }\end{array}$ \\
\hline
\end{tabular}




\begin{tabular}{|l|l|l|l|l|}
\hline $\begin{array}{l}\text { (Ferrein \& } \\
\text { Meyer, 2012) }\end{array}$ & $\begin{array}{l}\text { Flexander } \\
\text { Ferrein, } \\
\text { Thomas }\end{array}$ & $\begin{array}{l}\text { A Brief Overview of } \\
\text { Artificial Intelligence in } \\
\text { South Africa }\end{array}$ & $\begin{array}{l}\text { Association for } \\
\text { the Advancement } \\
\text { of Artificial } \\
\text { Intelligence. }\end{array}$ & $\begin{array}{l}\text { Presented the growth in AI research in South Africa } \\
\text { in recent years ranging from mobile robotics and } \\
\text { computational intelligence }\end{array}$ \\
\hline $\begin{array}{l}2011 \\
\text { Kowalski, } \\
2011)\end{array}$ & $\begin{array}{l}\text { Robert } \\
\text { Kowalski }\end{array}$ & $\begin{array}{l}\text { Artificial Intelligence } \\
\text { and Human Thinking }\end{array}$ & $\begin{array}{l}\text { Proceedings of the } \\
\text { Twenty-Second } \\
\text { International } \\
\text { Joint Conference } \\
\text { on Artificial } \\
\text { Intelligence }\end{array}$ & $\begin{array}{l}\text { Computational logic combined in an agent cycle, in order } \\
\text { to provide improvement in traditional logic and classical } \\
\text { decision theory. }\end{array}$ \\
\hline $\begin{array}{l}2010 \text { (Oroszi } \\
\text { \& Ruhland, } \\
2010)\end{array}$ & $\begin{array}{l}\text { F. Oroszi } \\
\text { and J. } \\
\text { Ruhland }\end{array}$ & $\begin{array}{l}\text { An early warning } \\
\text { system } \\
\text { for hospital acquired, }\end{array}$ & $\begin{array}{l}\text { 18 } \\
\text { Conference on } \\
\text { Information } \\
\text { Systems (ECIS) }\end{array}$ & $\begin{array}{l}\text { Developed warning system for hospitals which acts as } \\
\text { simple-reflex agent }\end{array}$ \\
\hline
\end{tabular}

Cooperation from humans is also essential to get a combination of human-level intelligence and machine intelligence (Shoham, 2019). Mok et al. (2019) analyzed the trend of growth on the beautiful journey of Artificial Intelligence between 2000 to 2015. Autor et al. (2019) highlighted opportunities for development of Artificial Intelligence in India. The author asserted that Artificial Intelligence could be a catalyst to accelerate progress and growth. Nowadays, Artificial Intelligence has vast potential in various sectors like finance, health care, law enforcement, transportation, agriculture, and environment conservation. The Indian government has recently constituted a task force specifically to promote Artificial Intelligence through various conferences for scaling up for NLP/ASR for Indian languages, structuring and mining public data, and healthcare. The government is also educating organizations about the risks associated with the Artificial Intelligence and recommending various steps to safeguard from those risks.

Shutters et al. (2016) surveyed to explore the role of Artificial Intelligence in sports. Many researchers are attempting to solve the problem of cancer by identifying negative patterns using intelligent machines. Many techniques of Artificial Intelligence are used by business investors for evaluating startups before making investments to reap rich returns quickly. Artificial Intelligence changes the nature of work which continues affecting our future. The author probed to find out the short-term and longterm future which reduces the execution time of tasks and makes more efficient by improving skills with machine intelligence. In sports, for e.g. cricket matches, Artificial Intelligence can enable to predict the scoring rate and current possible scenarios with more précised outcome of a player and/or the game. A company from the Netherlands uses artificial intelligence-based camera systems in Mobiles, which can create new content without the use of other facilities like the camera crew. Mobile camera system equipped with Artificial Intelligence uses a variety of sensors in which video and audio automatically adjust the cameras to capture the best pictures. Artificial Intelligence optimizes use of available bandwidth and the speed of the mobile data. Greg Brockman (2016) proposed a method of Artificial Intelligence with different fields. The author discussed about different areas of Artificial Intelligence such as language understanding, robotics, games, health sciences, problem solving, modeling, electro mechanical, medical areas and other companies and the author focused on intelligence in which humans solve large and complex queries with short methods. Artificial Intelligence has supremacy over natural intelligence. The task done by Artificial Intelligence machines can perform certain functions which are faster and better than the human being. It plays a very useful role in health sciences such as brain tumor and checks normal or abnormal waves that travel in the brain by using MRI. In computer games Artificial Intelligence has an important role in playing or watching games in computer for e.g.; GTA vice city and PUBG in mobiles phones. Artificial Intelligence is also used in path finding to fix the shortest path for travelling with the help of algorithms that helps computer to find best path in games so that people can cross the level easily. Technology in different fields will affect human life for many years. Amir Khosrowshahi (2018) shows various application of artificial intelligence in human life. Artificial Intelligence and its application are very useful in many different fields of human life such as engineering, business, complex statements, medicines, video games, a lot of areas of science and advertising also. The author has shown the role of Artificial Intelligence in traffic light which solves the problem of traffic light in order to reduce accidents. Artificial Intelligence is used in medical fields in endoscopy, MRI, Laser and in various surgical activities. James Kurose (2018) has focused on human interaction with Artificial Intelligence which is the project of the 21 st century, but actually, AI came in $384 \mathrm{BC}$ as a first deductive reasoning system. Alan Turing proposed an idea for computational 
thinking and laid the foundations of Artificial Intelligence. Human AI interaction is that as humans know that smart phones are more interactive than it was also just because AI sometimes might face difficulties in interaction but $\mathrm{AI}$ was the best. Understanding human emotions one of the major complications of Artificial Intelligence one is a deep learning Artificial Intelligence program which can tell that a person is a criminal or not by just looking at their faces. The author has not described in his research paper how civilization can be improved in the modern era.

\section{Conclusion}

Evolution of technology is a continuous process which results in continuous improvement and provides scope of further improvement to researchers. Automation using Artificial Intelligence brings many advantages to the society like lower rate of errors in manual activities, less time consuming, increased productivity and efficiency. Our paper attempts to summarize challenges in various fields of Artificial Intelligence. We have presented various approaches followed by different experts using existing technologies for making use of Artificial Intelligence in many applications in order to enhance manual efficiency and accuracy. Future Artificial Intelligence is expected to prevail everywhere in everything that humans are connected with. Our future research will be dealing with exploring successful AI based projects all over the world.

\section{References}

Anand, S., Sinha, A., Tiwari, U., \& Ray, S. (2014). Artificial Intelligence - Literature Review. The Centre for Internet and Society, India.

Autor, D.H. (2019). Work of the past, work of the future. AEA Papers and Proceedings, 109, 1-32. https://doi.org/10.1257/pandp.20191110

Bench-Capon, T.J.M., \& Dunne, P.E. (2007). Argumentation in artificial intelligence. Artificial Intelligence, 171(10-15), 619-641. https://doi.org/10.1016/j.artint.2007.05.001

Borden, M.A. (1998). Can Machine Paint? $5^{\text {th }}$ SGEM International Multidisciplinary Scientific Conferences on Social Sciences and Arts SGEM 2018, At Florence, Italy.

Breazeal, C., Gray, J., \& Berlin, M. (2009). An embodied cognition approach to mindreading skills for socially intelligent robots. International Journal of Robotics Research, 28(5), 656-680.

https://doi.org/10.1177/0278364909102796
Brockman, G. (2016). The Dawn of Artificial Intelligence. Testimony before U.S. Senate Subcommittee on Space, Science, and Competitiveness.

Brunette, E.S., Flemmer, R.C., \& Flemmer, C.L. (2009). A Review of artificial Intelligence. 4th International Conference on Autonomous Robots and Agents. ICARA 2009, 10-12 February, Wellington, New Zealand. https://doi.org/10.1109/ICARA.2000.4804025

Clodic, A., Alami, R., \& Chatila, R. (2014). Key elements for human-robot joint action. In Seibt, J., Hakli, R., \& Nørskov, M. (Eds.), Frontiers in Artificial Intelligence and Applications. IOS Press. https://doi.org/10.3233/978-1-61499-480-0-23

De Felice, F., Petrillo, A., \& Zomparelli, F. (2018). Prospective design of smart manufacturing: An Italian pilot case study. Manufacturing Letters, 15(Part B), 81-85. https://doi.org/10.1016/j.mfglet.2017.12.002

Ferrein, A., \& Meyer, T. (2012). A Brief Overview of Artificial Intelligence in South Africa. AI Magazine, 33(1), 99-103. https://doi.org/10.1609/aimag.v33i1.2357

Geortjel, B. (2007). Human-level artificial general intelligence and the possibility of a technological singularity: A reaction to Ray Kurzweil's The Singularity Is Near, and McDermott's critique of Kurzweil. Artificial Intelligence, 171(18), 1161-1173. https://doi.org/10.1016/j.artint.2007.10.011

Gupta, N. (2017). A Literature Survey on Artificial Intelligence. International Journal of Engineering Research \& Technology (IJERT). 5(19), 1-5.

Hardt, S.L., \& Rapaport, W.J. (1986). Recent and Current Artificial Intelligence. AI Magazine, 7(2), 91. https:// doi.org/10.1609/aimag.v7i2.543

Indrasen, P. (2017). How Artificial Intelligence in Impacting Real Life Every day. International Journal of Advance Research and Development, 2(10), 96-100.

Joolen, V.V. (2020). Artificial Intelligence and Robotics on the Battlefields of 2020. Strategy Research Project, USAWC class of 2020 .

Khosrowshahi, A. (2018). Testimony before the House Committee on Oversight and Government Reform Subcommittee on Information Technology.

Kowalski, R. (2011). Artificial Intelligence and Human Thinking. 22 $2^{\text {nd }}$ International Joint Conference on Artificial Intelligence (pp.11-16). AAAI Press. https:// doi.org/10.5591/978-1-57735-516-8/IJCAI11-013

Kurose, J. (2018). Testimony before the House Committee on Oversight and Government Reform Subcommittee on Information Technology.

Lemaignan, S., Warnier, M., Sisbot, E.A., Clodic, A., \& Alami, R. (2017). Artificial Cognition for Social 
Human-Robot Interaction: An Implementation. Artificial Intelligence, 247, 45-69.

https://doi.org/10.1016/j.artint.2016.07.002

Linde, H. (2019). A White Paper on the Future of Artificial Intelligence. White Paper, 1-10.

https://doi.org/10.13140/RG.2.2.32564.19844

Mahind, R., \& Patil, A. (2017). A Review Paper on General Concepts of Artificial Intelligence and Machine Learning. International Advanced Research Journal in Science, Engineering and Technology, 4(4), 79-82. https://doi.org/10.17148/IARJSET/ NCIARCSE.2017.22

Mok, R.M., \& Love, B.C. (2019). A non-spatial account of place and grid cells based on clustering models of concept learning. Nature Communications, 10, 5685. https://doi.org/10.1038/s41467-019-13760-8

Oke, S.A. (2008). Profitability. International Journal of Information and Management Science, 2(1), 133-136.

Oroszi, F., \& Ruhland, J. (2010). An Early Warning System for Hospital Acquired Pneumonia. ECIS 2010 Proceedings, 93.

Patil, A., Patted, L., Tenagi, M., Jahagirdar, V., Patil, M., \& Gautam, R. (2017). Artificial Intelligence as a tool in Civil Engineering. IOSR Journal of Computer Engineering (IOSR-JCE), 7(1), 36-39.

Perez, J.A., Fani, D., Daniele, R., \& Guang-Zhong, Y. (2017, June). Artificial Intelligence and Robotics. Retrieved from https://arxiv.org/ftp/arxiv/ papers/1803/1803.10813.pdf

Pérez-Ortiz, M., Jimenez-Fernandez, S., Gutierrez, P.A., Alexander, E., Hervás-Martínez, C., \& SalcedoSanz, S. (2016). A Review of Classification Problems and Algorithms in Renewable Energy Applications. Energies, 9(8), 607.

https://doi.org/10.3390/en9080607

Reilly, R. (1995). Sandy Ideas and Coloured Days: Some Computational Implications of Embodiment. Artificial Intelligence Review, 9, 305-322.

https://doi.org/10.1007/BF00849042

Renzi, C., Leali, F., Cavazzuti, M., \& Andrisano, A. (2014). A review on artificial intelligence applications to the optimal design of dedicated and reconfigurable manufacturing systems. The International Journal of Advanced Manufacturing Technology, 72, 403-418. https://doi.org/10.1007/s00170-014-5674-1

Shabbir, J., \& Anwer, T. (2015). Artificial Intelligence and its role in near future. Journal of Latex Class files. 14(8), $1-11$.

Shoham, Y. (2019). Artificial Intelligence Index Report. Steering Committee, Stanford University. Retrieved from https://hai.stanford.edu/sites/default/files/ai_ index_2019_report.pdf

Shutters, S.T., Muneepeerakul, R., \& Lobo, J. (2016). How hard is it for urban economies to become green? Environment and Planning B: Planning and Design, 43(1), 198-209.

https://doi.org/10.1177/0265813515600108

Strum, J., Stachniss, C., \& Burgard, W. (2011). A Probabilistic Framework for Learning Kinematic Models of Articulated Objects. Journal of Artificial Intelligence Research, 41, 477-526.

Tang, Y. (2013). Deep learning using linear support vector machines. arXiv preprint arXiv: 1306.0239.

\section{药 CHITKARA}

Chitkara University, Saraswati Kendra, SCO 160-161, Sector 9-C, Chandigarh, 160009, India

Copyright: [C2020 Madhu Dhiman et al.] This is an Open Access article published in Journal of Technology Management for Growing Economies by Chitkara University Publications. It is published with a Creative Commons Attribution- CC-BY 4.0 International License. This license permits unrestricted use, distribution, and reproduction in any medium, provided the original author and source are credited. 